Es muy difícil fechar las obras de Joan de Joanes a causa de su fidelidad a los esquemas una vez elaborados. Virgen... del Ermitage es más próxima a obras del pintor como Virgen del Venerable Agnesio (creada entre 1553 y 1557) y Virgen de la leche con San Juan Bautista y San Jerónimo (creada hacia 1570). Por eso podemos suponer que fuese pintada entre los mediados de 1550 y $1570^{4}$.

E. Solovieva

Museo del Ermitage

\title{
MARIANO BELLVER (1817-1876), ESCULTOR DE CÁMARA DE ISABEL II
}

\section{Datos biográficos}

Hijo de Francisco Bellver y Llop, también escultor como su padre. Nació en Madrid en 1817, estudiando en la Real Academia de Bellas Artes de San Fernando, siendo discípulo en esta noble institución del escultor de Cámara José Tomás.

Mariano Bellver contribuyó de forma activa al esplendor del Liceo Artístico y Literario de Madrid. Realizó numerosos trabajos, logrando una pública consideración de sus obras ${ }^{1}$.

Fue nombrado escultor de Cámara Honorario de Isabel II, jurando su cargo el 3 de mayo de 1860, ante don Buenaventura Carlos Arribau, Comendador de Número de la Real Casa y de la Orden de Carlos III, Jefe Superior de la Administración, Jubilado y Secretario de la Intendencia General de la Real Casa y Patrimonio.

De los documentos presentados por este artista dio fé el 11 de junio de 1871, el notario del Ilustre Colegio de Madrid don Pablo de la Lastra ${ }^{2}$. En un memorial que envía al Intendente de la Casa y Real Patrimonio el 21 de junio de 1875, señala que ha ejecutado muchas obras para el Palacio Real y otras que quedaron pendientes en las dolorosas y tristes jornadas del fatídico año de 1868 (año de la renuncia al trono y exilio a París de Isabel II), a continuación manifiesta que dejó una Purísima, igual a la que existe en el Real Monasterio del Escorial, la cual fue restaurada y pintada de nuevo ${ }^{3}$.

Falleció en Madrid, el 27 de abril de 1876.

Su obra

Ossorio y Bernard en su Diccionario Biográfico de Artistas Españoles del siglo XIX, hace una reseña de sus obras más notables ${ }^{4}$. Entre sus trabajos más importantes destacan:

\footnotetext{
${ }^{4}$ Los resultados de las investigaciones técnico-tecnológicas de la Virgen con el Niño, los Santos Juanitos y ángel, producidas en el laboratorio del Ermitage, no contradicen la atribución de este cuadro a la escuela pictórica española del siglo XVI.

1 Ossorio y Bernard, Manuel: Galería Biográfica de Artistas Españoles del Siglo XIX. Madrid. Ed. Giner. 1975, p. 76.

2 A.G.P. (Archivo General del Patrimonio). Expediente personal del escultor don Mariano Bellver. Caja $\mathrm{n}^{\circ}$ : $114 / 19$. Ma- $^{\circ}$ drid 11 de junio de 1875

${ }^{3}$ A.G.P. Expediente personal del escultor don Mariano Bellver. Caja n. ${ }^{\circ} 114 / 19$. Madrid 21 de junio de 1875.

${ }^{4}$ Ossorio y Bernard, Manuel: Galería Biográfica de Artistas Españoles del Siglo XIX, o.c..., p. 78.
}

$A E A, \mathrm{LXXV}, 2002,299$, pp. 293 a 334 
Para la exposición pública celebrada en la Academia de San Fernando de 1843, presentó una estatua de Juno en yeso.

Para la localidad de Tolosa, talló una imagen de madera policromada, dorada y estofada de San Juan Bautista predicando, de siete pies de altura, (2' $50 \mathrm{mts}$. aproximadamente).

Con destino a una de las iglesias del Real Sitio de Aranjuez (no especifica cual), realizó las siguientes imágenes: Cristo atado a la Columna, una Virgen de la Misericordia, y una Santa Lucia. Las dos primeras de tamaño natural, la tercera menor del tamaño natural. Todas ellas labradas en madera policromada, dorada y estofada.

Para el Noviciado de las Hijas de la Caridad de Madrid, realiza las siguientes imágenes: una estatua de San Vicente Paul, tallada en madera policromada, de tamaño natural, y una imagen de Jesucristo en el sepulcro de tamaño menor que el natural.

Con destino a la Capilla de San Pedro de la catedral de Sigüenza (Guadalajara), ejecuta en madera policromada, dorada y estofada el grupo de la Santísima Trinidad, aproximadamente hacia $1861^{5}$.

Para la iglesia parroquial de Espinosa de los Monteros, talla dos imagenes en madera policromada y de tamaño natural, que representan a San Lorenzo y a San Francisco Javier.

Para la nueva iglesia del Buen Suceso de Madrid lleva a cabo una imagen en madera policromada de Santa Irene.

Para Salamanca (no especifica lugar), una imagen de la Inmaculada Concepción.

Con destino a la iglesia parroquial de San Martín, en Madrid, y para su retablo del altar mayor, un grupo de su titular y dos imágenes laterales que representan a santos de órdenes religiosas, esculpidas en madera policromada, dorada y estofada.

Para el Liceo Artístico, modeló una ninfa en cera.

Para la iglesia de San Antonio del Prado talló en madera policromada una imagen de Nuestra Señora de la Providencia.

Una Inmaculada Concepción para los Italianos (sin especificar lugar y sitio).

La Asociación de la Corte de María le encargó una imagen de Nuestra Señora del Amor Hermoso para la iglesia de Santo Tomás de Madrid.

Para el Ilustre Colegio Notarial de Madrid talló un grupo en madera de Nuestra Señora del Buen Ruego pidiendo a Dios por las almas del Purgatorio.

Finalmente, con destino a la iglesia de San Antonio del Prado realizó una imagen de Nuestra Señora del Carmen ${ }^{6}$.

El historiador y critico de arte Juan Antonio Gaya Nuño, se equivoca al señalar que «debió trabajar en obras menores» ${ }^{7}$, ya que, según Ossorio en el repertorio de sus obras destaca una extensa producción de obras importantes para las iglesias de Madrid y otras en distintas iglesias parroquiales de pueblos y ciudades de España, y no digamos su grupo notable de la Santísima Trinidad para la Catedral de Sigüenza (Guadalajara).

Entre sus obras conservadas más importantes, destacan por su alto nivel artístico y gran calidad estética: el Grupo de la Santísima Trinidad que preside el retablo de la Capilla de San Pedro de la Catedral de Sigüenza (Guadalajara); y el altorrelieve colosal del grupo escultórico de San Martín a caballo en el acto de cortar con su espada parte de su capa, y entregársela a un pobre, en el retablo del altar mayor en la iglesia parroquial de San Martín de Madrid.

Ambas obras, de original composición, son muy expresivas y están ejecutadas en madera policromada, dorada y estofada. Siendo objeto del presente estudio.

\footnotetext{
${ }^{5}$ Ossorio y Bernard, Manuel: Galería Biográfica de Artistas Españoles del Siglo xIX, o.c..., p. 78.

${ }^{6}$ Ossorio y Bernard, Manuel: Galera Biográfica de Artistas Españoles del Siglo xIX, o.c, pp. 76 y 78.

7 Gaya Nuño, Juan Antonio: Arte Español del Siglo xix. Vol. XIX. Col. «Ars Hispaniae» Ed. «Plus Ultra». Madrid. 1966, p. 190.
}

AEA, LXXV, 2002, 299, pp. 293 a 334 


\section{Grupo de la Santísima Trinidad. Catedral de Sigüenza (Guadalajara)}

En la Capilla de San Pedro de la Catedral de Sigüenza, se venera en su retablo mayor un magnífico grupo de la Santísima Trinidad, obra del escultor de Cámara de Isabel II, Mariano Bellver, ejecutado en madera policromada, en el año $1861^{\circ}$. Encargo del Cabildo al artista en el citado año.

Muestra la típica iconografía trinitaria, de Dios Padre Todopoderoso sedente, con rostro barbado, y de actitud dulce, afable y bondadoso, sosteniendo con su mano derecha un cetro y junto a él, el globo celeste, que simboliza el universo, porta un bellísimo manto beig y túnica gris. Soberbio es el estudio de los pliegues tanto de la túnica como del manto.

Jesucristo al otro lado, también se muestra sentado al igual que su Padre. Con un semblante dulce y bondadoso en su rostro. Su mano izquierda y hombro sostiene la Cruz redentora de nuestra salvación y el brazo derecho lo dobla, señalando con su mano la paloma del Espíritu Santo, que destaca entre un haz de rayos luminosos de sol. Lleva manto de color púrpura y túnica de azul claro.

Dicho grupo se asienta sobre un hermoso trono de nubes, todo acompañado por dos deliciosos ángeles que en vuelo, uno con las manos juntas, contempla la escena y el otro mirando de frente al espectador, señala con su mano izquierda la obra. Al mismo tiempo se muestran, en el centro y en las esquinas, grupos alados de querubines.

Grupo inspirado en los grandes modelos escultóricos del barroco español, de bella composición y de espléndida policromía y carnaciones, que decora el interior de la bellísima Catedral de Sigüenza.

Altorrelieve colosal en madera policromada, dorada y estofada, que muestra a San Martín, montado a caballo en el acto de partir su capa con la espada y entregarla a un necesitado. Iglesia de San Martín. Madrid.

En el interior de la iglesia parroquial de San Martín, antigua Portacoeli, se conserva en el camarín del retablo del altar mayor un soberbio y colosal altorrelieve en madera policromada dorada y estofada, de aproximadamente 3'50 mts. de altura, que muestra a San Martín a caballo en el momento de partir con su espada su capa y entregársela a un mendigo ${ }^{9}$.

Tanto el santo a caballo, como el indigente son figuras casi exentas, en altorrelieve, al fondo entre nubes se muestra una muralla romana con torreones.

San Martín, nacido en la Panoia (actual Hungria), hijo de un tribuno romano, era de profesión militar ${ }^{10}$. Mariano Bellver lo muestra vestido, con indumentaria de soldado romano a caballo, portando una bellísima túnica de color púrpura, y con un vistoso casco de plumas con penachos sobre su cabeza, en el acto de partir su capa para entregársela a un pobre. Magnífico

${ }^{8}$ Sarthou Carreres, Carlos: Catedrales de España (Su pasado y su presente). Madrid. Ed. Espasa-Calpe, 1946, p. 310.

- Federico, Aurelio de: La Catedral de Sigüenza. Colección «Los Monumentos Cardinales de España». N: XVI. Madrid. Ed. «Plus Ultra». 1954, p. 30.

- Azcárate y Ristori, José María de y otros: Inventario de la Ciudad de Guadalajara y su Provincia. Tomo II. Madrid. Ministerio de Cultura. Dirección General de Bellas Artes y Archivo. 1983, p. 162.

- Sarthou Carreres, Carlos y Pedro Navascués Palacios: Catedrales (Monumentos, Tesoros y Lugares de España). Madrid. Ed. Espasa- Calpe. 1994, p. 287.

9 Tormo y Monzó, Elías: Las Iglesias del Antiguo Madrid. Reed. De dos fascículos publicados en 1927. Madrid. Instituto de España. 1972, pp. 133 y 135.

- Sainz de Robles, Federico Carlos: Madrid. De la Puerta del Sol a la Villa de Fuencarral. El Refugio. TomoIV. Madrid. Instituto de Estudios Madrileños. Excmo. Ayuntamiento de Madrid. Ed. Espasa-Calpe. 1980, pp. 1329-30.

${ }^{10}$ Roig, Juan Ferrando: Iconografía de los Santos. Barcelona. Ed. Omega. 1950, p. 193.

AEA, LXXV, 2002, 299, pp. 293 a 334 

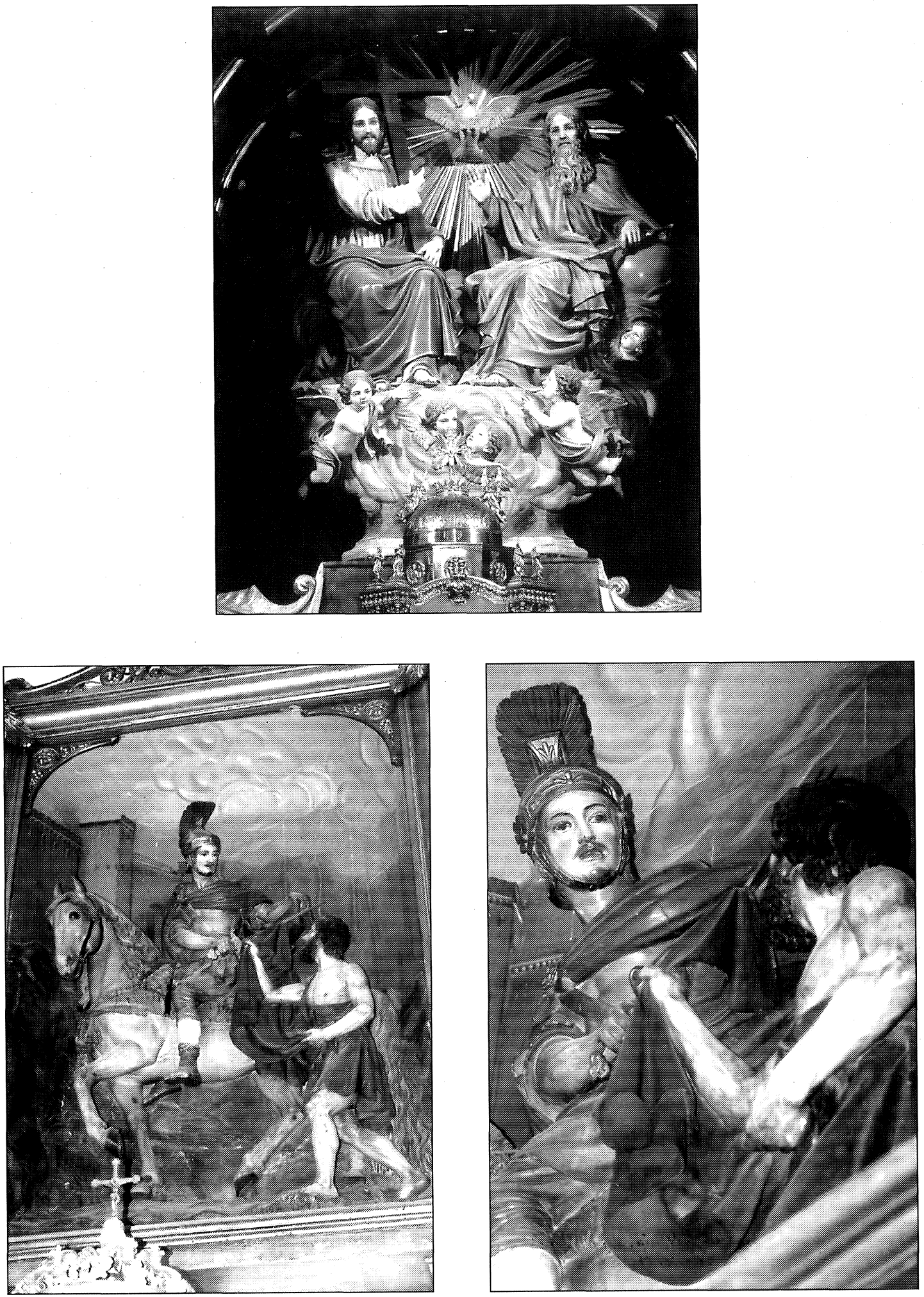

Fig. 1. Mariano Bellver: Grupo de la Santísima Trinidad. Catedral de Siguienza (Guadalajara).

Fig. 2: Mariano Bellver: Grupo de San Martín a caballo. Conjunto general de la obra. Iglesia de San Martín. Madrid. Fig. 3. Mariano Bellver: Grupo de San Martín a caballo. Detalle. Iglesia de San Martín. Madrid. 
es el rostro vuelto del santo, de bella expresión, muy bien conseguida por nuestro escultor, así como la noble y equilibrada anatomía del caballo, como también el excelente modelado anatómico del mendigo que recibe parte de la túnica, muy bien estudiada su anatomía del natural, con estupenda policromía y carnaciones, con profundo y estudiado escorzo.

La indumentaria del santo esta muy bien lograda por Mariano Bellver, inspirada en la estatuaria romana de la época imperial.

El escultor ha tratado el altorrelieve, como si se tratara de un cuadro pictórico, de excelentes calidades.

A ambos extremos de este colosal altorrelieve y en el altar mayor, Bellver presentó dos imágenes en madera policromada, de tamaño menor que el natural, que representan a San Benito y a Santa Gertrudis ${ }^{11}$, actualmente en paradero desconocido.

\section{DOCUMENTACION}

I

\section{Mariano Bellver es nombrado escultor de Cámara de la reina Isabel II}

(A.G.P. Expediente Personal del escultor don Mariano Bellver. Caja no: 114/19)

La Reina Na. S $\mathrm{S}^{\mathrm{a}}$. (q.D.g):se ha dignado conceder a V. Los honores de Escultor de Cámara.De Real Orden lo digo a V. para su conocimiento, satisfacción y demás efectos. Dios guarde a V. muchos años. Palacio diez de febrero de mil ochocientos sesenta $=\mathrm{Al}$ margen hay una rubrica.=José de Ybarra.= A Don Mariano Bellver.= En el menbrete dice: «Yntendencia General de la Real Casa y Patrimonio»=.

Don Mariano Bellver, \& jurais servir bien y fielmente a la Reina $\mathrm{D}^{\mathrm{a}}$ Isabel Segunda en la plaza de Escultor de Cámara Honorario para que habeis sido nombrado, procurando en todo su provecho y apartando su daño; y dar cuenta a los Gefes de cuanto seguir que pueda ser contrarío a su Real Servicio y perjudicial a su Real Persona e ínterés? = R. Si juro.= Si a si lo hicieseis, Dios os guarde, y si no, os lo demande. =R, Amén..= Don Buenaventura Carlos Aribau, Comendador de Número dela Real y Distinguida Orden de Carlos Tercero, Gefe Superior de Administración jubilado, Secretario de la Yntendencia General dela Real Casa y Patrimonio. \&.\&.

Certifico: Que D. Mariano Bellver ha prestado en este dia el juramento que antecede en manos del Sr. D. José de Ybarra, Yntendente General dela misma, a mi presencia.= Palacio tres de mayo de mil ochocientos sesenta $=$. Buen. ${ }^{\text {a }}$ Carlos Aribau. $=$ Hay un sello.=

Corresponden literalmente los documentos insertos con sus originales, que me fueron exhibidos por D. Mariano Bellver, a quien se los devolví, deque doy fé y a que me remito. Ya su instancia y el infrascrito notario del Colegio Territorial de esta Corte y vecino dela misma espido el presente testimonio en un pliego de sello décimo en Madrid a once de junio de mil ochocientos setenta y cinco.=

Rubricado: Pablo de la Lastra.

II

\section{Memorial del escultor Mariano Bellver solicitando de nuevo la plaza de escultor de Cámara Honorario}

(A.G.P. Expediente Personal del escultor Mariano Bellver. Caja n. ${ }^{\circ}: 114 / 19$ ).

Madrid, 21 de junio de 1875.

Señor:

Dn. Mariano Bellver, vecino de esta corte, habitante en la Plaza de la Cebada, $\mathrm{n}^{\circ} .12$, portal, puesto a los R.R.P.P. de V.M. con la mayor sumisión y respeto expone:

" Gómez Moreno, María Elena: Pintura y Escultura Españolas del Siglo XIX. Madrid. Colección «Summa Artis». Vol. XXXV. Ed. Espasa-Calpe. 1993, p. 123.

$A E A, \mathrm{LXXV}, 2002,299$, pp. 293 a 334 
Que en 10 de febrero de 1860 fue nombrado por S.M. Su Augusta Madre. Escultor de Cámara Honorario cuyo cargo juro en manos del Sr. Intendente General de la RealCasa y Patrimonio en 3 de mayo de 1860, según se acredita con las copias testimoniadas qe. tiene la honra de acompañar.

Muchas son las obras que tiene ejecutadas en el Rl. Palacio y otras que quedan pendientes en la dolorosa y triste jornada de 1868, entre ellas una Purísima igual a la que existe en el Real Monasterio del Escorial, la cual fue restaurada y pintada de nuevo por el exponente.

Los Augustos Padres de V.M. ofrecieron diferentes veces al recurrente agradecerle con la primera vacante que ocurriese de Escultor de numero y habiéndose verificado esta por fallecimiento del insigne y malogrado Dn. José Piquer.

A.V.M. Suplica rendidamente que por un acto de su inagotable munificiencia sedigne nombrar al exponente para dicha plaza vacante de Escultor de numero de la Real Casa, gracia que espera de V.M. cuya vida queda rogando al Todopoderoso,dilate muchos años para la felicidad de esta desventurada Nación.

Madrid, 21 de junio de 1875

Señor

A.L.R.R. P.P. de V.M.

Rubricado: Mariano Bellver.

José Luis MeLendreras Gimeno

\section{PLATA DOMÉSTICA ESPAÑOLA DEL SIGLO DE LOS AUSTRIAS MENORES}

En sendas colecciones privadas de Pamplona se guardan un jarro de pico, una fuente, un taller de mesa y una bacía de plata. Todas las piezas pertenecen a la platería civil española del siglo XVII, momento en que se desarrolló uno de sus capítulos más originales ' ; a la vez reflejan la evolución del gusto a lo largo de los reinados de los Austrias Menores e ilustran múltiples inventarios de la época ${ }^{2}$. Pero mientras que de las dos primeras se han conservado bastantes ejemplares, el taller y la bacía resultan excepcionales; sin embargo, en su estudio hemos optado por un criterio cronológico.

El jarro de pico y la fuente siguen la estética de la época de Felipe III y aparentemente forman un juego de aguamanil, pero provienen de familias distintas.

La interpretación del jarro $^{3}$, una de las creaciones más genuinas de la platería castellana, es muy depurada ${ }^{4}$. Las costillas pareadas, el espejo oval, la moldura superior, el pico con artesón, todo responde al tipo plenamente codificado. De las tres variantes del jarro castellano, el que ahora comentamos está más próximo a la versión cortesana, cuyo prototipo marcó García de Sahugún ${ }^{5}$, como delata el asa en forma de ce.

Con el jarro madrileño se han relacionado los ejemplares vascos y los navarros que aparecen en el libro de exámenes de los plateros de Pamplona ${ }^{6}$; estos últimos, sin embargo, presentan asa en 3, otra de las opciones del jarro cortesano. Pero en Navarra contamos también con

1 J. M. Cruz Valdovinos: «De las platerías castellanas a la cortesana», Boletín del Museo e Instituto Camón Aznar, 1983, p. 17.

${ }^{2}$ L. Arbeteta Mira: «Espacio privado: La casa de Calderón . «Museo del discreto», Calderón de la Barca y la España del Barroco, Madrid, 2000, pp. 77-80

${ }^{3}$ Medidas: alto $17 \mathrm{~cm}$, base $7,5 \mathrm{~cm}$, boca $10,5 \mathrm{~cm}$. Peso: $808 \mathrm{gr}$.

4 J. M. Cruz Valdovinos: «Jarros de pico en la platería hispánica I y II», Galería Antiqvaria, n¹36 y 137, 1996, pp. 2231 y $40-49$.

5 Ibidem, «Jarros de ...I», p. 30 y «Jarros de... II», p. 40; F. A. Martín: Catálogo de la plata del Patrimonio nacional, Madrid, 1978, p. 25, A. Fernández, R. Munoa y J. Rabasco: Enciclopedia de la plata española y virreinal americana, Madrid, 1982, p. 351, J. M. Cruz Valdovinos: Platería en la Fundación Lázaro Galdiano, Madrid, 2000, p. 155.

${ }^{6}$ J. M. Cruz Valdovinos: «Jarros de... II», pp. 42 y 44, M. ${ }^{a}$ C. García Gaínza: Dibujos antiguos de los plateros de Pamplona, Pamplona, 1991, $\mathrm{n}^{\circ} 1$ y 18.

AEA, LXXV, 2002, 299, pp. 293 a 334 